\title{
Time and Diffusion Lesion Size in Major Anterior Circulation Ischemic Strokes
}

\section{Citation}

Hakimelahi, R., B. A. Vachha, W. A. Copen, G. D. E. Papini, J. He, M. M. Higazi, M. H. Lev, et al. 2014. Time and Diffusion Lesion Size in Major Anterior Circulation Ischemic Strokes. Stroke 45, no. 10: 2936-2941. doi:10.1161/STROKEAHA.114.005644

\section{Published Version}

doi:10.1161/STROKEAHA.114.005644

\section{Permanent link}

http://nrs.harvard.edu/urn-3:HUL.InstRepos:32680457

\section{Terms of Use}

This article was downloaded from Harvard University's DASH repository, and is made available under the terms and conditions applicable to Open Access Policy Articles, as set forth at http:// nrs.harvard.edu/urn-3:HUL.InstRepos:dash.current.terms-of-use\#OAP

\section{Share Your Story}

The Harvard community has made this article openly available.

Please share how this access benefits you. Submit a story.

Accessibility 


\section{Time and Diffusion Lesion Size in Major Anterior Circulation Ischemic Strokes}

Reza Hakimelahi, MD; Behroze A. Vachha, MD, PhD; William A Copen, MD; Giacomo D.E. Papini, MD; Julian He, MD; Mahmoud M. Higazi, MD; Michael H. Lev, MD; Pamela W.

Schaefer, MD; Albert J. Yoo, MD; Lee H. Schwamm, MD; R. Gilberto González*, MD, PhD

Neuroradiology Division and the Stroke Service, Massachusetts General Hospital, Harvard

Medical School, 55 Fruit St, Boston, MA 02114, USA

* Corresponding author: R. Gilberto González, MD, PhD, GRB-273A, 55 Fruit St, Boston, MA 02114

Email: rggonzalez@mgh.harvard.edu Tel: 617-726-8320 Fax: 617-724-3338

Cover Title: Time and diffusion lesion size in acute stroke

Keywords: Ischemic stroke; CT angiography; MRI; diffusion; anterior circulation

Subject Codes: [44] Acute Cerebral Infarction [58] Computerized tomography and Magnetic Resonance Imaging

Figures: 5

Tables: 1

Supplementary Figures: 5; Supplementary Tables: 1 


\begin{abstract}
:
Background: Major anterior circulation ischemic strokes caused by occlusion of the distal internal carotid artery (ICA) or proximal middle cerebral artery (MCA) or both account for about one-third of ischemic strokes with mostly poor outcomes. These strokes are treatable by IV-tPA and endovascular methods. However, dynamics of infarct growth in these strokes are poorly documented. The purpose was to help understand infarct growth dynamics by measuring acute infarct size with DWI at known times after stroke onset in patients with documented ICA/MCA occlusions.
\end{abstract}

Methods: Retrospectively, we included 47 consecutive patients with documented ICA/MCA occlusions who underwent DWI within 30h of stroke onset. Prospectively, 139 patients were identified using the same inclusion criteria. DWI lesion volumes were measured and correlated to time since stroke onset. Perfusion data was reviewed in those who underwent perfusion imaging.

Results: Acute infarct volumes ranged from 0.41-318.3ml. Infarct size and time did not correlate $\left(\mathrm{R}^{2}=0.001\right)$. The majority of patients had DWI lesions that were less than $25 \%$ the territory at risk $(<70 \mathrm{ml})$ whether they were imaged $<$ or $>8 \mathrm{~h}$ after stroke onset. DWI lesions corresponded to areas of greatly reduced perfusion.

Conclusions: Poor correlation between infarct volume and time after stroke onset suggests that there are factors more powerful than time in determining infarct size within the first $30 \mathrm{~h}$. The observations suggest that highly variable cerebral perfusion via the collateral circulation may primarily determine infarct growth dynamics. If verified, clinical implications include the possibility of treating many patients outside traditional time windows. 


\section{Introduction}

Acute ischemic stroke is the fourth leading cause of death in the United States and the leading cause of severe disability in adults. ${ }^{1}$ Cerebral artery occlusions of the terminal internal carotid artery (ICA) and/or the proximal middle cerebral artery (MCA) represent 30-40\% of all acute ischemic strokes, but account for the majority of poor outcomes. ${ }^{2}$ Current treatment approaches for these strokes are commonly restricted by the time elapsed since stroke onset. For intravenous tissue plasminogen (IV tPA), the currently approved treatment window is 3-4.5 hours from the time of stroke onset. ${ }^{3,4}$ For intra-arterial therapy (IAT) the time window is typically 0-6 hours for thrombolysis and 0-8 hours for mechanical therapies. ${ }^{5}$ This adherence to time windows is driven by the idea that there is rapid infarct growth while ischemia is left untreated ${ }^{6}$ and that treatment efficacy rapidly decreases with time. ${ }^{7-10}$

A limitation of the current approach is that it does not take into consideration patientspecific cerebrovascular physiology. ${ }^{11}$ While quantitative estimates of the pace of neuronal loss in human ischemic stroke may be applicable on a population level, the actual rate of neuronal loss in patients with proximal anterior circulation artery occlusion (ACO) strokes may vary considerably from patient to patient, and is influenced by a number of factors, most importantly the effectiveness of cerebral perfusion via the collateral circulation in maintaining the reversibly threatened, hypoperfused but still viable tissue outside of the infarct. ${ }^{12-14}$ Recently the timebased approach has been challenged as treatments have been shown to be effective outside the traditional time windows. ${ }^{15,16}$ 
The dynamics of infarct growth in patients with proximal ACO strokes are not well documented. Experimental animal stroke models suggest that the most common pattern of infarct growth is logarithmic. ${ }^{17,18}$ Although infarct growth patterns in human brain have not specifically been evaluated, linear infarct growth is commonly assumed. ${ }^{6}$ The purpose of this study was to gain insights into infarct growth dynamics in patients with documented proximal ACO by measuring acute infarct size using diffusion weighted MRI up to 30 hours after stroke onset.

\section{Methods}

\section{Patient selection}

This study consisted of retrospective and prospective components. Both components were compliant with the Health Insurance Portability and Accountability Act (HIPAA) and were approved by our institutional review board (IRB).

The retrospective study utilized data from a published study by Copen et al. ${ }^{19}$ In that study, all patients who presented to the emergency department (ED) of our hospital from June 2005 through December 2006 with symptoms suggesting an acute stroke syndrome were screened. We also prospectively identified patients who presented to our hospital ED with stroke symptoms from January 2008 to October 2009.

Inclusion criteria were: 1 . Patients presented to the ED with acute symptoms of stroke within 30 hours of symptom onset. 2. MR imaging including a DWI scan demonstrating an acute anterior circulation infarct; 3. CT angiography (CTA) or MR angiography (MRA) of the head demonstrating a proximal anterior circulation artery occlusion (i.e. terminal ICA and/or proximal MCA (M1 and/or M2 origin); 3. All imaging was performed before any thrombolytic or other 
recanalization therapies. Stroke onset time for each patient this study was the estimate entered in the clinical record by the stroke neurologist caring for the patient. Patients who had unknown time of stroke onset or had "wake-up" strokes were not included in the study.

\section{Imaging acquisition}

All imaging studies were requested by ED physicians based on clinical need and were not influenced by these studies.

Computed tomography angiography

In the retrospective study, CTA was performed from the C6 vertebral body level through the circle of Willis following the injection of 100-140 ml of Isovue $61.2 \mathrm{~g} / 100 \mathrm{~mL}$ (Bracco Diagnostics, Princeton, NJ) at a rate of $3 \mathrm{ml} / \mathrm{s}$. Imaging was triggered 25 seconds after contrast injection (40 seconds for patients with atrial fibrillation). Immediately afterward, a second set of images was obtained from the aortic arch to the skull base. The parameters were $2.5-\mathrm{mm}$ slice thickness, 1.25-mm reconstruction interval, $140 \mathrm{kV}, 220-250 \mathrm{~mA}$, and 0.75:1 pitch.

In the prospective study, CT angiography was performed from the vertex to the aortic arch following injection of $80-120 \mathrm{ml}$ of Isovue 370 at a rate of $3.5 \mathrm{ml} / \mathrm{s}$. SmartPrep (GE Medical Systems, Milwaukee, WI) was used with a region of interest $1 \mathrm{~cm}$ below the carina covering the lumen of the ascending aorta. Scanning began 10 seconds after the region of interest reached $75 \mathrm{HU}$. The parameters were $1.25-\mathrm{mm}$ slice thickness, $0.625-\mathrm{mm}$ reconstruction interval, $120 \mathrm{kV}, 350-800 \mathrm{~mA}$, and 0.516:1 pitch.

Magnetic resonance imaging 
MR imaging was performed on a 1.5 T Signa whole body scanner (GE Medical Systems). Axial DWI were obtained using single-shot, spin echo echoplanar imaging with the following parameters: TR $5000 \mathrm{~ms}$; TE 80 to $110 \mathrm{~ms}$; b-value $1000 \mathrm{~s} / \mathrm{mm} 2$; field of view $22 \mathrm{~cm}$; matrix size $128 \times 128$, zero-filled to 256 x 256, and slice thickness of $5 \mathrm{~mm}$ with a 1-mm inter-slice gap. As many slices as needed to cover the entire brain were acquired. For each slice a sequence including an image without diffusion gradients plus high-gradient-factor images in six directions were acquired. This was repeated five times and resulted in 35 images for each slice and a total imaging time of less than 4 minutes. Double inversion pulses were used to reduce eddy current effects. MRA images of the head were acquired using a three dimensional time-of-flight technique with $25^{\circ}$ flip angle, TR/TE of $36 / 6.8 \mathrm{~ms}, 18$-cm field of view, and a 512 x 512 matrix. One hundred and eleven transverse images were reconstructed with a section thickness of 1.4 $\mathrm{mm}$ and spacing of $0.7 \mathrm{~mm}$.

\section{Post processing image analysis}

In the retrospective study, lesions on DWI maps were outlined visually by a research technologist. In the prospective study, DWI abnormalities were outlined visually by two research fellows. All analyses were performed using a semi-automated commercially available image analysis program (Analyze 8.0; AnalyzeDirect, Overland Park, KS). These were done blinded to time of stroke onset and the locations of arterial occlusion. Diffusion lesion volumes were calculated using the $b=1000$ diffusion weighted images with the apparent diffusion coefficient maps used for confirmation of reduced diffusion. Regression analysis was performed to assess inter-rater reliability for the 2 individuals who measured the DWI lesion volumes of the prospective cohort. The analysis was based on 41 of 139 prospective cohort patient data sets 
analyzed by both reviewers. The analysis revealed a slope of 1.09 , intercept of $1.5 \mathrm{ml}, \mathrm{R}^{2}=0.95$ with $p<0.0001$, indicating acceptable inter-rater reliability.

Statistical analysis

Two tailed Spearman's rank analyses were performed to assess for a significant correlation between time from ictus and DWI lesion volume. A finding was deemed significant if the $\mathrm{p}$ value was $<0.05$. Statistical analyses were performed using SPSS statistical software (release 20.0 for Windows; SPSS, Chicago, IL).

\section{Results}

Table 1 shows demographic and imaging data. Of the 47 patients in the retrospective cohort, there were 29 (62\%) patients with DWI infarct volumes $\leq 70 \mathrm{ml}$, which is less than $25 \%$ of the territory at risk. In the prospective cohort of 139 consecutive patients, 103 (74\%) had DWI infarct volumes $\leq 70 \mathrm{ml}$. For the total sample of 186 patients, acute infarct volumes ranged from 0.41 to $318.3 \mathrm{ml}$. Figure 1 shows representative diffusion weighted MR images of the first and then every eleventh case of the prospective data set. This figure provides a visual illustration of the randomness of infarct size with respect to time. Figure 2 is a scatter plot of acute infarct size with respect to time since stroke onset for all 186 patients; there was no correlation between infarct volume and time $\left(\mathrm{R}^{2}=0.001\right.$ and $\left.\mathrm{p}=0.712\right)$. Mean infarct volumes were not significantly different when grouped into temporal cohorts (Supplemental Table I).

We investigated the possible roles of occlusion site heterogeneity and uncertainty of time of stroke onset. A subset of 56 patients (mean age: 70 years, SD +/- 15, males: 34 ) with only MCA M1 occlusions were evaluated. The patients in this subset appeared well within 30 minutes of when their stroke was discovered. Similar to the entire group, there was no correlation 
between diffusion lesion volume and time since stroke onset $\left(\mathrm{R}^{2}=0.017\right.$ and $\left.\mathrm{p}=0.342\right)$. There were also no correlations between time after stroke onset and DWI lesion volume in patients with only M1 occlusions (Supplemental Figure I), ICA occlusions (Supplemental Figure II), and T occlusions (Supplemental Figure III). The most homogenous subset consisted of 46 patients with witnessed stroke onset and with M1 segment MCA occlusions. A scatter plot of these patients is shown in Figure 3. There was no correlation between DWI lesion volume and time since witnessed stroke onset $\left(R^{2}=0.000\right.$ and $\left.p=0.959\right)$. Finally, we investigated potential bias by the 2 research fellow that calculated lesion volumes in the prospective cohort (Figures IV and V) finding similar results for both individuals.

To explore the range of infarct growth rates in these patients, we estimated the rate of infarct growth assuming linearity from time of stroke onset to the point of imaging. Figure 4 illustrates the very wide range of infarct growth rates calculated in this fashion. The mean rate for the retrospective cohort was $23 \mathrm{ml} / \mathrm{hr}$ with a standard deviation of $36 \mathrm{ml} / \mathrm{hr}$ and a range from $<1$ to $170 \mathrm{ml} / \mathrm{hr}$. The mean rate for the prospective cohort was $12 \mathrm{ml} / \mathrm{hr}$ with a standard deviation of $15 \mathrm{ml} / \mathrm{hr}$ and a range from $<1$ to $77 \mathrm{ml} / \mathrm{hr}$. For those in the prospective cohort with witnessed stroke onset, the mean growth rate was $12 \mathrm{ml} / \mathrm{hr}$ (SD of $13.8 \mathrm{ml} / \mathrm{hr}$ ) and a range of $<1$ to $69 \mathrm{ml} / \mathrm{hr}$. Some patients had very rapid apparent infarct growth. For example, of 139 patients with M1 occlusions, 30 who were imaged within 8 hours after ictus had DWI lesion volumes >70ml. Assuming linear lesion growth, 16 of these patients would have had DWI volumes $>70 \mathrm{ml}$ if they had been imaged even 2 hours or less after ictus (Supplemental Figure SIV). We thus estimate that $\sim 12 \%$ of patients with MCA occlusions in our study had DWI lesion volumes $>70 \mathrm{ml}$ by 2 hours after stroke onset. 
To help understand the low correlation between DWI lesion volume size and time after stroke onset, imaging data was further reviewed in all patients who also had a perfusion MRI (PWI) study performed. A total of 128 patients met these criteria. In the retrospective cohort, all 47 patients had PWI. . In this cohort all patients with a small DWI lesion volume (<70ml) had identifiable perfusion beyond the lesion, although it was abnormal with a mean transit time (MTT)/DWI mismatch of $>100 \%$ in all such patients ${ }^{20}$. A review of all 71 patients in the prospective cohort also revealed that in all patients who had DWI abnormalities that were significantly smaller than the territory at risk, perfusion was observable beyond the diffusion abnormality, and collateral circulation vessels were well seen on the CTA. In all patients whose collateral vessels were not well seen by CTA, and who had very reduced perfusion shown by PWI, the DWI lesion involved virtually the entire territory at risk. Figure 5 illustrates these observations in 2 patients with right MCA occlusions who were scanned $\sim 6$ hours after stroke onset.

\section{Discussion}

There were 3 major findings in patients with proximal anterior circulation arterial occlusions: a lack of correlation between DWI lesion size and time after stroke onset; a relatively small size of these infarcts in the majority of patients; and a very wide range of infarct growth rates, assuming linear growth. These findings suggest that there are factors more important than time in determining the infarct size within the first 24 hours. One potential factor that could explain all of the observations is a very wide variability in the cerebral perfusion via the collateral circulation accompanying a major anterior circulation occlusion. ${ }^{12-14,19}$ 
We considered potential confounders. One possibility was heterogeneity in occlusion sites. However, the same lack of correlation persisted when we evaluated patients with only M1, terminal ICA and T occlusions. Another possible confounder was low precision in the estimated time between stroke onset and imaging. However, when we examined the data from patients who had witnessed stroke onset, again we found no correlation between time and diffusion lesion volume. This absence of correlation would be expected if there is large variability in the cerebral perfusion via the collateral circulation in proximal ACO patients.

The high proportion of patients who presented with infarct volumes $<70 \mathrm{ml}$ may have important implications for treating stroke patients. Indeed the majority of patients had these relatively small volumes even after 8 hours after stroke onset. Since the MCA territory typically comprises $300 \mathrm{ml}$ or more of the cerebrum, the findings indicate that $3 / 4$ or more of potentially endangered tissue may still be viable many hours beyond the typical time cut-off for endovascular treatment, which is commonly 8 hours or less from the time last seen well. Thus these patients are potentially eligible for treatment. These data also support prior reports that have suggested that time alone does not provide an accurate or complete picture of stroke pathophysiology. ${ }^{11,15,19}$ We also estimated that a significant proportion of patients had DWI lesion volumes $>70 \mathrm{ml}$ by 2 hours after stroke onset, which would also have important implications on whether to proceed with thrombolytic therapy at early time points. It may be possible to use markers other than time, such as a tissue-based marker such as one contingent on differences in the diffusion and FLAIR signal as is being currently tested in the MR WITNESS trial (see at clinicaltrials.gov/show/NCT01282242).

It is often assumed that infarct growth is linear. ${ }^{6}$ However infarct growth is logarithmic in animal stroke models. ${ }^{17,18}$ There are few published studies examining infarct growth in 
humans, but in a study from our group in which patients were imaged several times over the first few days after stroke onset, we found that more than $80 \%$ of patients with MCA occlusions the diffusion abnormality grew very little over 24 hours whether or not there was a persistence of the occlusion. ${ }^{21}$ This was most consistent with a logarithmic growth pattern. Even assuming a linear pattern of infarct growth, we found a very wide distribution of growth rates that ranged from less than $1 \mathrm{ml} / \mathrm{hr}$ to over $70 \mathrm{ml} / \mathrm{hr}$ (see also Figure 4). The widely quoted average rate of neuronal loss of 1.9 million neurons $/ \mathrm{min}$ corresponds to an infarct growth rate of $5.4 \mathrm{ml} / \mathrm{hr}^{6}$ which is approximately half the average rate for the patients in this study. This difference may be explained by the fact that only major anterior circulation occlusion stroke patients are considered in the current study. But the unexpected observation of a wide range of infarct growth rates suggests that there may be many patients with slow infarct growth rates that may benefit from treatment targeting the occluded vessel.

The findings presented here are best explained by wide variations in the cerebral perfusion provided by the collateral circulation. In all patients who had diffusion abnormalities that were smaller than the territory at risk, we observed evidence for perfusion beyond the diffusion abnormality that was provided by collateral circulation observed on the CTA. When the collaterals appeared poor by CTA, there was poor perfusion on PWI and the DWI lesion was noted to involve virtually the entire vascular territory at risk. However, other factors such as degree of ischemic preconditioning, systemic blood pressure and blood glucose may contribute to individual differences in infarct growth rates. Further research on this is needed.

In acute ischemic stroke due to proximal anterior circulation occlusions, a smaller infarct volume at presentation is the single best predictor of functional outcome in patients. ${ }^{22}$ Yoo et al demonstrated that in patients with anterior circulation stroke undergoing endovascular therapy, 
those with initial infarct volumes $<70 \mathrm{ml}$ who underwent early recanalization had the best clinical outcomes and the least infarct growth. ${ }^{23}$ Additional studies have identified a volume of > $70 \mathrm{ml}$ as highly predictive of poor clinical outcome irrespective of the time of presentation. ${ }^{24,25}$ However, the $70 \mathrm{ml}$ volume threshold is in the early stages of validation and further investigations may prove that another infarct core volume larger or smaller than $70 \mathrm{ml}$ is superior. It is also important to note that while there is general agreement that the size of the core infarct is an important factor in patient outcomes, it has been suggested that there may be better predictors of outcomes such as certain perfusion measurements. ${ }^{26-29}$

Currently, intravenous thrombolytic therapy is administered in only $1 \%-7 \%$ of cases (high performing centers approach 15-20\%), with most patients ineligible because they present outside the 3 - 4.5 hour treatment window. ${ }^{30-33}$ Proximal anterior circulation artery occlusions may respond well to intra-arterial thrombolysis and mechanical thrombectomy; however these treatments are also typically restricted by adherence to time windows of 6 and 8 hours respectively from the time of stroke onset. ${ }^{5}$ In the pooled analysis of the MERCI and Multi MERCI trials there was no association between time (to treatment or reperfusion) and outcomes, and $40 \%$ of the patients reperfused at $>/=6.9$ hours achieved independent functional outcomes. ${ }^{34}$ Other studies have demonstrated an extension of the 3-4.5 hour window for a novel thrombolytic agent up to 9 hours without a significant increased complication of intracranial hemorrhage. ${ }^{16}$ However, large randomized trials have not been performed using these approaches. While this study was not designed to evaluate longitudinal growth of infarct size at various time points post stroke onset, a prior study by our group demonstrated stability of diffusion/perfusion MRI abnormalities, in a series of patients with ICA or proximal MCA occlusions that persisted in a majority of the patients up to 24 hours. ${ }^{21}$ 
In light of the results of these previous studies, our finding that many patients imaged $>8$ hours after stroke onset have small infarct volumes, suggests opportunities for treatment outside traditional time windows. Our study does not establish that all patients with small infarct volumes would benefit from treatment. It is possible that patients presenting late may have altered tissue physiology that puts them at additional risk. It may be that their collaterals are so good that their final infarcts will remain small without revascularization. Clearly, additional studies are needed to evaluate outcomes in patients treated outside traditional time windows. Nonetheless our study adds to the body of literature that suggests that with recent developments in neuroimaging, time since onset of stroke may not be the only or the most important factor for determining who should be considered for treatment.

\section{Conclusions}

There is a lack of correlation between infarct volume and time after stroke onset in patients with proximal anterior circulation occlusion strokes that is best explained by wide variations in perfusion via the collateral circulation, although other factors may also be contributors. Some of these patients have large infarcts even at very early time points. However, most of these patients have small ischemic lesions, regardless of the time since symptom onset, and this suggests that it may be possible to treat many more patients outside traditional time windows.

\section{Disclosures:}

Dr Schwamm receives research funding from NINDS for a trial of mri-based patient selection for IV Thrombolysis in an extended window (MR WITNESS). Genentech provides alteplase at no 
cost and supplementary site financial support. He is on the international steering committee for DIAS 3,4 and DSMB for Penumbra 3D trial. Dr. Yoo receives research funding from Penumbra Inc. for core imaging lab activities for START and THERAPY trials and PICS and FIRST studies; from Covidien Inc. as investigator for SWIFT Prime (significant), and NINDS for the Angiographic core lab for the MR CLEAN trial. Dr. Lev receives research funding from GE Healthcare and is a Millennium Pharmaceutical Consultant. The other authors have no disclosures. Dr. Higazi received a national grant support from the Egyptian government and Minia University, Egypt 


\section{References}

1. Go AS, Mozaffarian D, Roger VL, Benjamin EJ, Berry JD, Borden WB, et al. Heart disease and stroke statistics--2013 update: A report from the american heart association. Circulation. 2013;127:e6-e245

2. Gonzalez RG, Furie KL, Goldmacher GV, Smith WS, Kamalian S, Payabvash S, et al. Good outcome rate of $35 \%$ in iv-tpa-treated patients with computed tomography angiography confirmed severe anterior circulation occlusive stroke. Stroke. $2013 ; 44: 3109-3113$

3. Del Zoppo GJ, Saver JL, Jauch EC, Adams HP, Jr., American Heart Association Stroke C. Expansion of the time window for treatment of acute ischemic stroke with intravenous tissue plasminogen activator: A science advisory from the american heart association/american stroke association. Stroke. 2009;40:2945-2948

4. Lees KR, Bluhmki E, von Kummer R, Brott TG, Toni D, Grotta JC, et al. Time to treatment with intravenous alteplase and outcome in stroke: An updated pooled analysis of ecass, atlantis, ninds, and epithet trials. Lancet. 2010;375:1695-1703

5. Jauch EC, Saver JL, Adams HP, Jr., Bruno A, Connors JJ, Demaerschalk BM, et al. Guidelines for the early management of patients with acute ischemic stroke: A guideline for healthcare professionals from the american heart association/american stroke association. Stroke. 2013;44:870-947

6. Saver JL. Time is brain--quantified. Stroke. 2006;37:263-266

7. Clark WM, Wissman S, Albers GW, Jhamandas JH, Madden KP, Hamilton S. Recombinant tissue-type plasminogen activator (alteplase) for ischemic stroke 3 to 5 
hours after symptom onset. The atlantis study: A randomized controlled trial. Alteplase thrombolysis for acute noninterventional therapy in ischemic stroke. JAMA. $1999 ; 282: 2019-2026$

8. Hacke W, Kaste M, Fieschi C, Toni D, Lesaffre E, von Kummer R, et al. Intravenous thrombolysis with recombinant tissue plasminogen activator for acute hemispheric stroke. The european cooperative acute stroke study (ecass). JAMA. 1995;274:1017-1025

9. Hacke W, Kaste M, Fieschi C, von Kummer R, Davalos A, Meier D, et al. Randomised double-blind placebo-controlled trial of thrombolytic therapy with intravenous alteplase in acute ischaemic stroke (ecass ii). Second european-australasian acute stroke study investigators. Lancet. 1998;352:1245-1251

10. Khatri P, Abruzzo T, Yeatts SD, Nichols C, Broderick JP, Tomsick TA, et al. Good clinical outcome after ischemic stroke with successful revascularization is timedependent. Neurology. 2009;73:1066-1072

11. Gonzalez RG. Imaging-guided acute ischemic stroke therapy: From "time is brain" to "physiology is brain". AJNR Am J Neuroradiol. 2006;27:728-735

12. Bang OY, Saver JL, Buck BH, Alger JR, Starkman S, Ovbiagele B, et al. Impact of collateral flow on tissue fate in acute ischaemic stroke. J Neurol Neurosurg Psychiatry. 2008;79:625-629

13. Christoforidis GA, Mohammad Y, Kehagias D, Avutu B, Slivka AP. Angiographic assessment of pial collaterals as a prognostic indicator following intra-arterial thrombolysis for acute ischemic stroke. AJNR Am J Neuroradiol. 2005;26:1789-1797

14. Liebeskind DS. Collaterals in acute stroke: Beyond the clot. Neuroimaging Clin N Am. 2005; $15: 553-573, x$ 
15. Abou-Chebl A. Endovascular treatment of acute ischemic stroke may be safely performed with no time window limit in appropriately selected patients. Stroke. 2010;41:1996-2000

16. Furlan AJ, Eyding D, Albers GW, Al-Rawi Y, Lees KR, Rowley HA, et al. Dose escalation of desmoteplase for acute ischemic stroke (dedas): Evidence of safety and efficacy 3 to 9 hours after stroke onset. Stroke. 2006;37:1227-1231

17. Bardutzky J, Shen Q, Bouley J, Sotak CH, Duong TQ, Fisher M. Perfusion and diffusion imaging in acute focal cerebral ischemia: Temporal vs. Spatial resolution. Brain research. 2005;1043:155-162

18. Neumann-Haefelin T, Kastrup A, de Crespigny A, Yenari MA, Ringer T, Sun GH, et al. Serial mri after transient focal cerebral ischemia in rats: Dynamics of tissue injury, bloodbrain barrier damage, and edema formation. Stroke. 2000;31:1965-1972; discussion 1972-1963

19. Copen WA, Rezai Gharai L, Barak ER, Schwamm LH, Wu O, Kamalian S, et al. Existence of the diffusion-perfusion mismatch within 24 hours after onset of acute stroke: Dependence on proximal arterial occlusion. Radiology. 2009;250:878-886

20. Hakimelahi R, Yoo AJ, He J, Schwamm LH, Lev MH, Schaefer PW, et al. Rapid identification of a major diffusion/perfusion mismatch in distal internal carotid artery or middle cerebral artery ischemic stroke. BMC Neurol. 2012;12:132

21. Gonzalez RG, Hakimelahi R, Schaefer PW, Roccatagliata L, Sorensen AG, Singhal AB. Stability of large diffusion/perfusion mismatch in anterior circulation strokes for 4 or more hours. BMC Neurol. 2010;10:13 
22. Yoo AJ, Chaudhry ZA, Nogueira RG, Lev MH, Schaefer PW, Schwamm LH, et al. Infarct volume is a pivotal biomarker after intra-arterial stroke therapy. Stroke. 2012;43:1323-1330

23. Yoo AJ, Verduzco LA, Schaefer PW, Hirsch JA, Rabinov JD, Gonzalez RG. Mri-based selection for intra-arterial stroke therapy: Value of pretreatment diffusion-weighted imaging lesion volume in selecting patients with acute stroke who will benefit from early recanalization. Stroke. 2009;40:2046-2054

24. Sanak D, Nosal V, Horak D, Bartkova A, Zelenak K, Herzig R, et al. Impact of diffusionweighted mri-measured initial cerebral infarction volume on clinical outcome in acute stroke patients with middle cerebral artery occlusion treated by thrombolysis.

Neuroradiology. 2006;48:632-639

25. Lansberg MG, Straka M, Kemp S, Mlynash M, Wechsler LR, Jovin TG, et al. Mri profile and response to endovascular reperfusion after stroke (defuse 2): A prospective cohort study. Lancet neurology. 2012;11:860-867

26. Bang OY, Saver JL, Alger JR, Starkman S, Ovbiagele B, Liebeskind DS, et al. Determinants of the distribution and severity of hypoperfusion in patients with ischemic stroke. Neurology. 2008;71:1804-1811

27. Nicoli F, Lafaye de Micheaux P, Girard N. Perfusion-weighted imaging-derived collateral flow index is a predictor of mca $\mathrm{m} 1$ recanalization after $\mathrm{i} . \mathrm{V}$. Thrombolysis. AJNR Am J Neuroradiol. 2013;34:107-114

28. Olivot JM, Mlynash M, Inoue M, Marks MP, Wheeler HM, Kemp S, et al. Hypoperfusion intensity ratio predicts infarct progression and functional outcome in the defuse 2 cohort. Stroke. 2014;45:1018-1023 
29. Mlynash M, Lansberg MG, De Silva DA, Lee J, Christensen S, Straka M, et al. Refining the definition of the malignant profile: Insights from the defuse-epithet pooled data set. Stroke. 2011;42:1270-1275

30. Barber PA, Zhang J, Demchuk AM, Hill MD, Buchan AM. Why are stroke patients excluded from tpa therapy? An analysis of patient eligibility. Neurology. 2001;56:10151020

31. Cocho D, Belvis R, Marti-Fabregas J, Molina-Porcel L, Diaz-Manera J, Aleu A, et al. Reasons for exclusion from thrombolytic therapy following acute ischemic stroke. Neurology. 2005;64:719-720

32. Katzan IL, Furlan AJ, Lloyd LE, Frank JI, Harper DL, Hinchey JA, et al. Use of tissuetype plasminogen activator for acute ischemic stroke: The cleveland area experience. JAMA. 2000;283:1151-1158

33. Kleindorfer D, Lindsell CJ, Brass L, Koroshetz W, Broderick JP. National us estimates of recombinant tissue plasminogen activator use: Icd-9 codes substantially underestimate. Stroke. 2008;39:924-928

34. Nogueira RG, Smith WS, Sung G, Duckwiler G, Walker G, Roberts R, et al. Effect of time to reperfusion on clinical outcome of anterior circulation strokes treated with thrombectomy: Pooled analysis of the merci and multi merci trials. Stroke. 2011;42:31443149 


\section{Figure Legends}

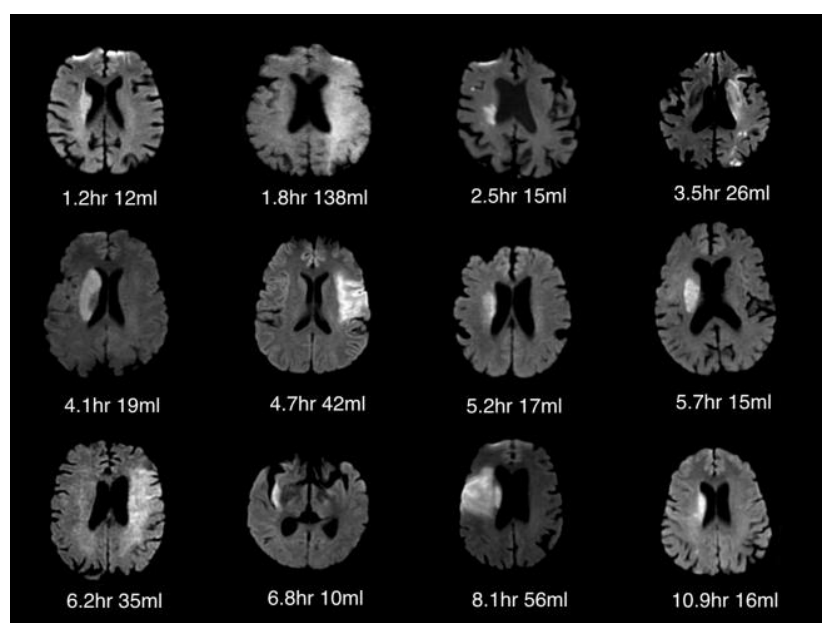

Figure 1. Representative diffusion weighted images. The images are from the prospective data set and are listed in order of imaging time after stroke onset. The first and then every 11th case of the prospective data set are shown. Time from stroke onset and DWI lesion volumes are listed under each image. A relationship between time since ictus onset and DWI volume is not apparent. Small infarct volumes $(<50 \mathrm{ml})$ are observed in 10 of 12 patients.

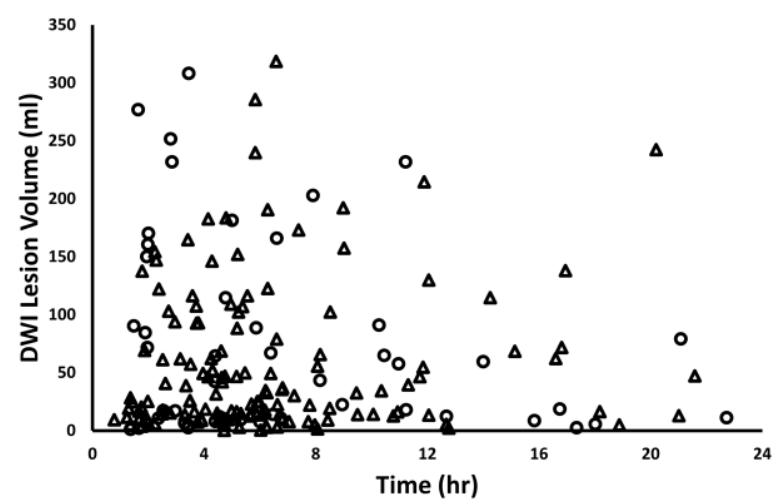


Figure 2. DWI lesion volume versus estimated time since stroke onset. A scatter plot of all stroke cases $(\mathrm{N}=186)$ that includes the DWI lesion volume from an MRI study performed at an estimated time after stroke onset. Open circles are from the retrospective cohort and the triangles are from the prospective cohort.

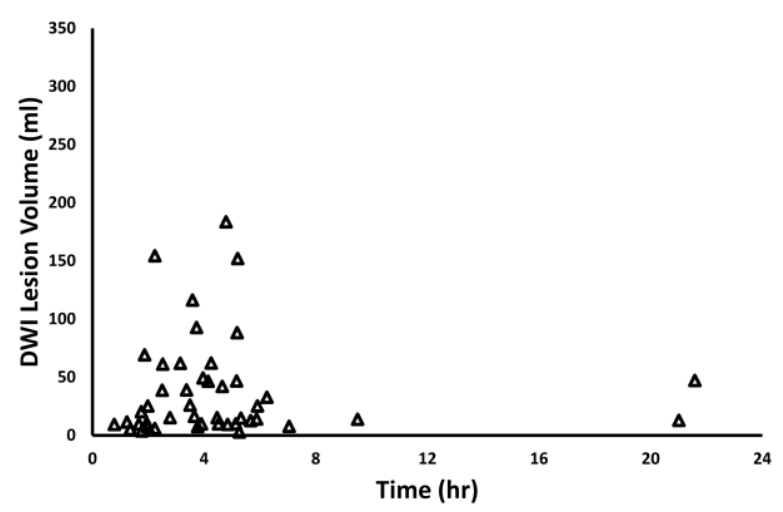

Figure 3. DWI lesion volume versus time scatter plot for patients with witnessed stroke onset and M1 occlusion only. Lesion volumes are plotted against time since stroke onset in 46 patients (mean age: $69 \mathrm{y}, \mathrm{SD}+/-14$, males: 25). No significant correlation was observed $(\mathrm{R} 2=0.000$ and $\mathrm{P}$ value $=0.959)$. 


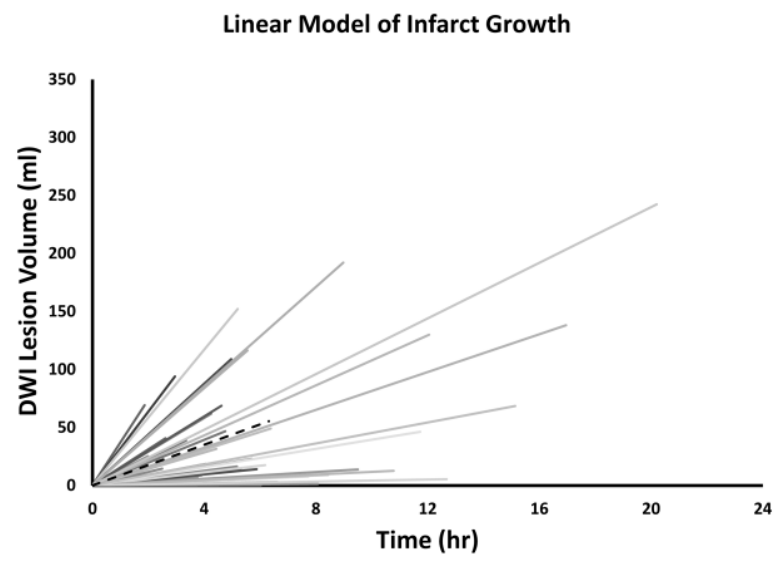

Figure 4. Linear model of infarct growth. Depicted are the estimated growths of infarcts assuming linearity for every third patient of the prospective cohort (47 of 139 cases). The dotted line represents average infarct growth of all the prospective cases, $12 \mathrm{ml} / \mathrm{hr}$. Each line stops at the time of imaging after stroke onset for that patient.

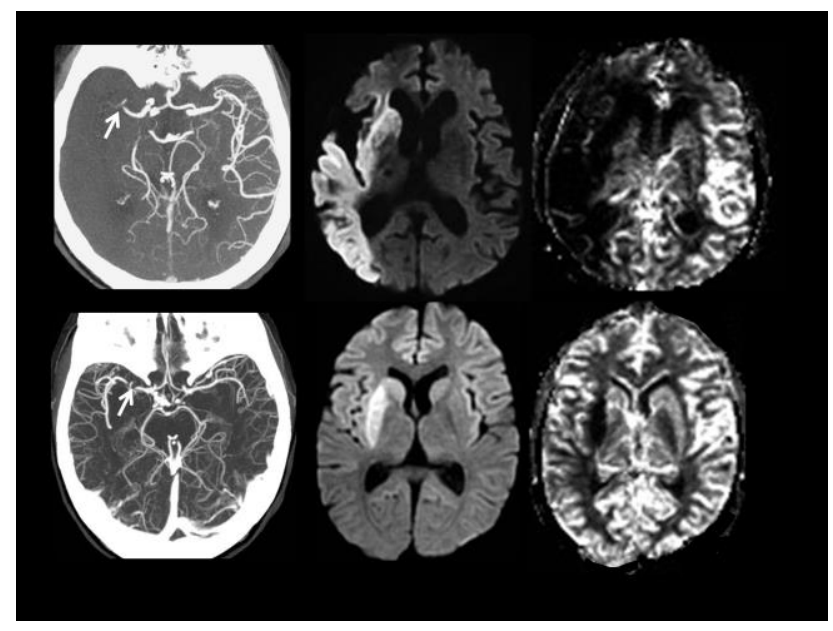

Figure 5. Diffusion lesion volume and perfusion via collateral circulation. The images are from two patients that were imaged $\sim 6$ hours after stroke onset. Both patients had a right MCA M1 occlusion (arrows). Upper row images are from a patient with a large DWI lesion that 
encompasses nearly the entire right MCA territory (top middle) that has very low CBF (top right) and very few collateral vessels on CTA (top left). The lower row images are from a patient with a small DWI lesion confined to the region of the right basal ganglia (lower middle). The remainder of the right MCA territory in this patient has normal CBF (bottom right) and robust collateral vessels on CTA (bottom left). 
Tables

Table 1. Demographic and imaging data

\begin{tabular}{|c|c|c|c|}
\hline Retrospective cohort & All & DWI lesion $\leq 70 \mathrm{ml}$ & DWI lesion > 70ml \\
\hline Number (\%) & $47(100 \%)$ & $29(62 \%)$ & $18(38 \%)$ \\
\hline Age (Mean; SD) & $68 ; 18.5$ & $69 ; 17.1$ & $67 ; 20.9$ \\
\hline Male; Female & $22 ; 25$ & $13 ; 16$ & $9 ; 9$ \\
\hline $\begin{array}{l}\text { DWI volume (median; } \\
\text { range) }\end{array}$ & $43.7 ; 1.2-308.3$ & $12.2 ; 1.2-67.1$ & $163.4 ; 71.8-308.3$ \\
\hline
\end{tabular}

\begin{tabular}{llll} 
Prospective cohort & All & DWI lesion $\leq 70$ ml & DWI lesion $>$ 70ml \\
\hline Number (\%) & $139(100 \%)$ & $103(74 \%)$ & $36(26 \%)$ \\
Age (Mean; SD) & $69 ; 15.6$ & $71 ; 15.1$ & $66 ; 17$ \\
Male; Female & $75 ; 64$ & $55 ; 48$ & $20 ; 16$ \\
$\begin{array}{l}\text { DWI volume (median; } \\
\text { range) }\end{array}$ & $28.5 ; 0.41-318.5$ & $16.6 ; 0.4-69.3$ & $133.8 ; 71.9-318.5$ \\
& & & \\
DWI = diffusion weighted images; SD: standard deviation; Age in years; DWI volume in ml
\end{tabular}

\section{Supplemental Methods:}

For the total sample of 186 patients, the mean infarct volume was $61 \mathrm{ml}$ and was similar when grouped into 3-hour temporal cohorts (Table I). There were no significant differences in diffusion abnormality volumes between the temporal cohorts (ANOVA p=0.98). Using $70 \mathrm{ml}$ as a threshold, the majority of patients fell under this threshold regardless of whether they were imaged less than or more than 8 hours after stroke onset.

To further address the possible roles of occlusion site heterogeneity, the distribution of DWI volumes versus time after stroke onset in patients with MCA, distal ICA and "T" (carotid terminus, proximal MCA and proximal ACA) occlusions was evaluated. There was no 
relationship between the DWI lesion volumes and time since stroke onset in any of these subsets. Figures I-III illustrate these findings.

There was high inter-rater reliability between the two research fellows in measuring DWI maps $\left(\mathrm{R}^{2}=0.95\right.$ with $\left.\mathrm{p}<0.0001\right)$. Figures IV and V illustrate the distribution of DWI lesion volume with respect to time after stroke onset in subsets of the prospective cohort whose volumes were measured by each of the two research fellows. There was no correlation between the DWI lesion volumes and time since stroke onset in either of the two subsets as is clearly illustrated in the figures.

Figure VI illustrates linear model of infarct growth in all patients with M1 occlusion, a large DWI lesion volume (>70 ml) and presenting within 8 hours after stroke. Assuming a linear DWI lesion growth, approximately half of these patients would have had a rapid infarct growth with DWI lesion volumes larger than $70 \mathrm{ml}$ within the first 2 hours after stroke onset. This means that approximately 1 out of 10 patients with MCA occlusion in our study had a rapid infarct growth. These patients might be at high risk of treatment complications even within the accepted time windows. 


\section{Supplemental Tables:}

Table I. Mean and Median DWI volumes grouped into temporal cohorts

\begin{tabular}{llllll} 
Time (hr) & N & $\begin{array}{l}\text { Mean DWI } \\
\text { volume }(\mathbf{m l})\end{array}$ & $\begin{array}{l}\text { Median DWI } \\
\text { volume }(\mathbf{m l})\end{array}$ & Range $(\mathbf{m l})$ & IQR \\
\hline $0-3$ & 42 & 65 & 23 & 276 & 97 \\
$>3-6$ & 68 & 62 & 41 & 308 & 80 \\
$>6-9$ & 37 & 60 & 30 & 318 & 56 \\
$>9-12$ & 16 & 69 & 43 & 219 & 68 \\
$>12-15$ & 8 & 43 & 13 & 128 & 96 \\
$>15-18$ & 7 & 53 & 62 & 135 & 63 \\
$>18$ & 8 & 53 & 15 & 237 & 64
\end{tabular}

DWI: diffusion weighted images; IQR: interquartile range 


\section{Supplemental Figures and Figure Legends:}

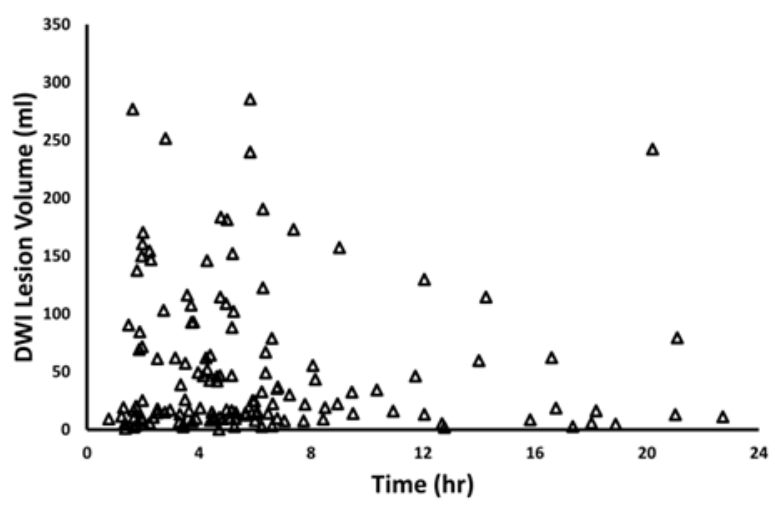

Figure I. Distribution of DWI lesion volume with respect to time after stroke onset in all patients with $\mathrm{M} 1$ occlusion $\left(\mathrm{N}=139 ; \mathrm{R}^{2}=0.003 ; \mathrm{p}=0.53\right)$.

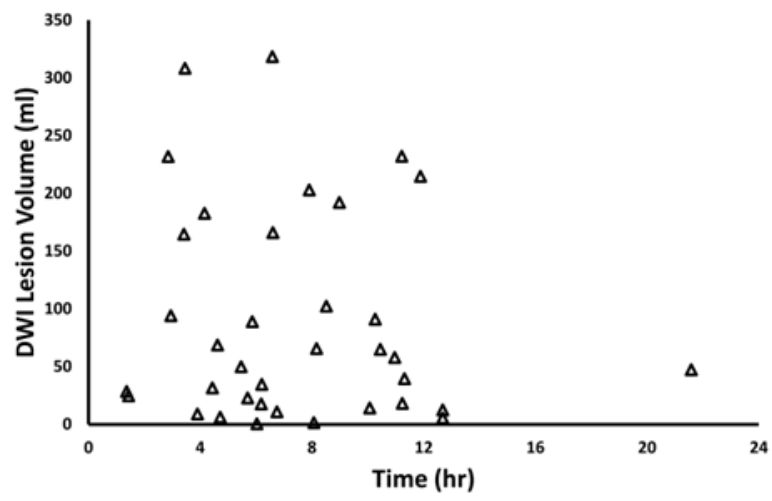

Figure II. Distribution of DWI lesion volume with respect to time after stroke onset in all patients with terminal ICA occlusion $\left(\mathrm{N}=36 ; \mathrm{R}^{2}=0.01 ; \mathrm{p}=0.52\right)$. 


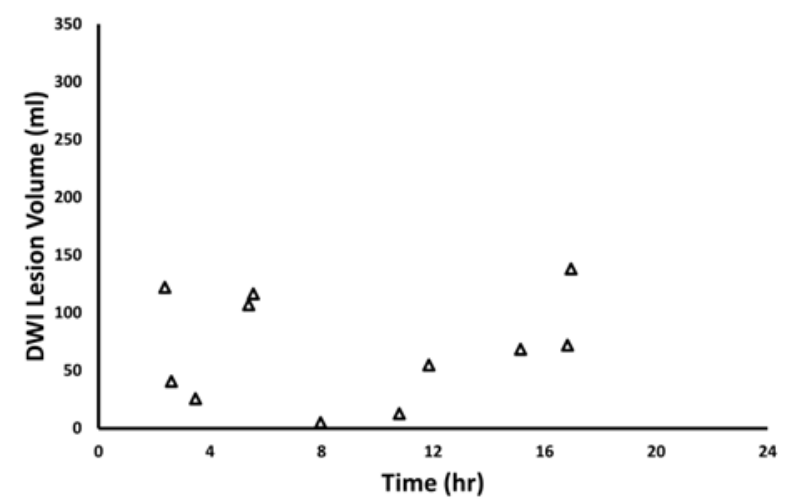

Figure III. Distribution of DWI lesion volume with respect to time after stroke onset in all patients with a $\mathrm{T}$ lesion $\left(\mathrm{N}=11 ; \mathrm{R}^{2}=0.01 ; \mathrm{p}=0.77\right)$.

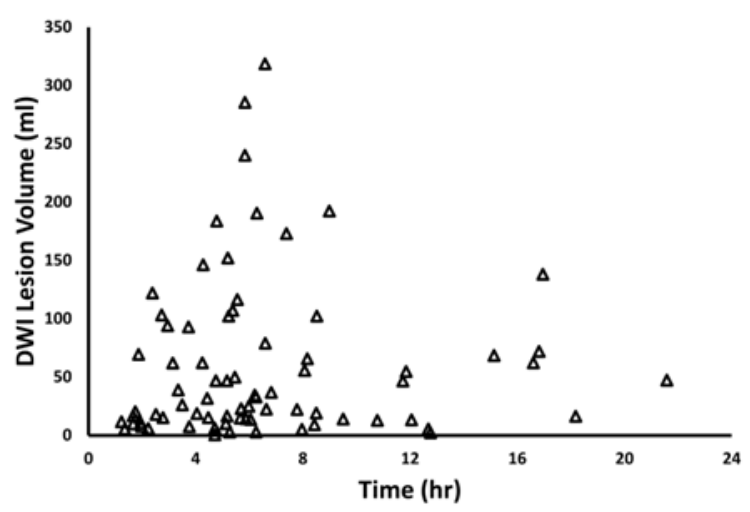

Figure IV. Distribution of DWI lesion volume with respect to time after stroke onset in patients from the prospective cohort whose volumes were measured by the first research fellow $(\mathrm{N}=75$; $\left.\mathrm{R}^{2}=0.001 ; \mathrm{p}=0.83\right)$. 


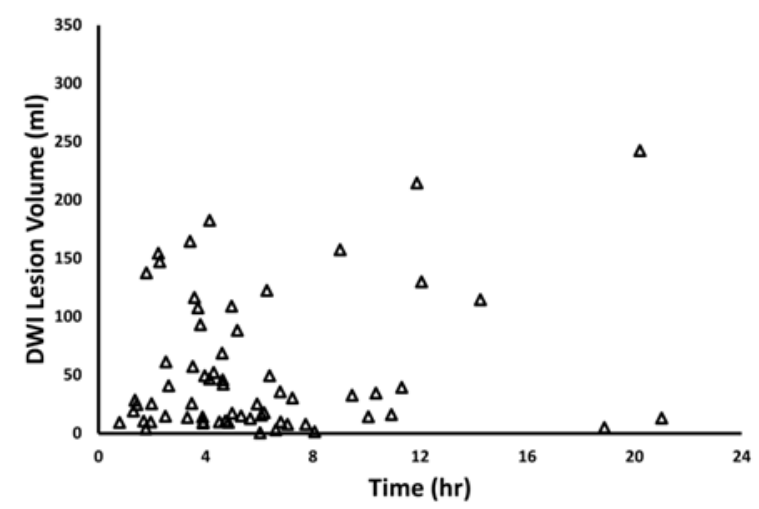

Figure V. Distribution of DWI lesion volume with respect to time after stroke onset in patients from the prospective cohort whose volumes were measured by the second research fellow $\left(\mathrm{N}=64 ; \mathrm{R}^{2}=0.034 ; \mathrm{p}=0.15\right)$.

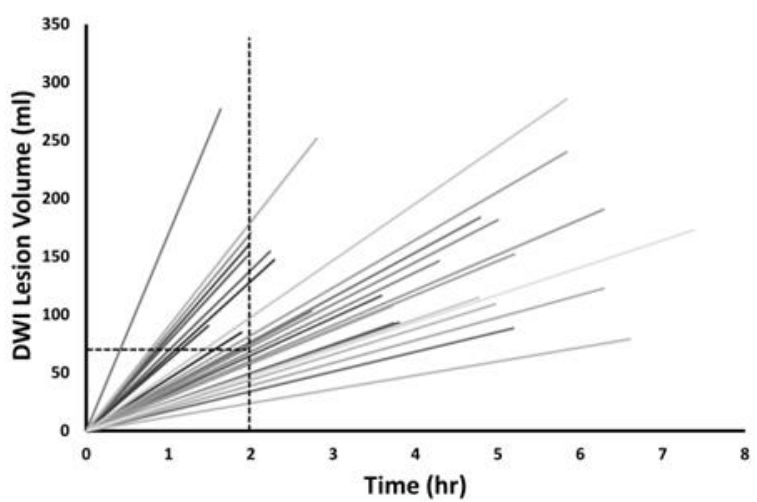

Figure VI. Estimation of number of patients with DWI lesion volumes $>70 \mathrm{ml}$ by 2 hours after stroke onset. An estimate of infarct growth was made assuming linearity for all patients with M1 occlusion and a DWI lesion volume $>70 \mathrm{ml}$ who were imaged within 8 hours after stroke onset $(\mathrm{N}=30)$. The vertical dashed line is at 2 hours after stroke onset; the horizontal dashed line is at a 
DWI lesion volume of $70 \mathrm{ml}$. A total of 16 patient of the 30 patients had an estimated DWI lesion volume of $>70 \mathrm{ml}$ by 2 hours after stroke. 